\title{
TheEffect of Education Program Based on Health Belief Model on Decreasing Blood Sugar Levels in Diabetic Type 2 Patients in Zahedan
}

\author{
Iraj Zareban ${ }^{1}$, Shamsaddin Niknami ${ }^{2,}$, Alireza Hidarnia ${ }^{2}$, Fatemeh Rakhshani ${ }^{1}$, Mahmood \\ Karimy $^{3}$, Mohsen Shamsi ${ }^{3}$ \\ ${ }^{1}$ Health Promotion Research Center, Zahedan University of Medical Sciences, Zahedan, IR Iran \\ 2 Department of Health Education, Faculty of Medical Sciences, Tarbiat Modares University, Tehran, IR Iran \\ 3 Department of Health Education, Faculty of Health, Arak University of Medical Sciences, Arak, IR Iran \\ ${ }^{*}$ Corresponding author: Shamsaddin Niknami, Department of Health Education, Faculty of Medical Sciences, Tarbiat Modares University, Jalal Ale Ahmad Highway, P.O. Box: 14115-111, \\ Tehran, IR Iran. Tel.: +98-2182883549, Fax:+98-2182883558, Email: Niknamis@modares.ac.ir.
}

Received: October 21, 2012; Revised: March 06, 2013; Accepted: March 21, 2013

Background: Diabetes as the most common metabolic disorder is an important global challenge. Diabetes needs self-care for one's entire life.

Objectives: The aim of study was detecting the effect of health belief model program on decreasing blood sugar level in diabetic patients of Zahedan city in 2011.

Patients and Methods: After choosing 138 diabetic type 2 patients from Zahedan diabetic center, they were divided into two random groups (case and control groups each of them 69 patients). Data was collected using a questionnaire based on the health belief model, and checklist related to patient practices. Reliability and validity of questionnaire was examined. Data collected before the intervention and three and six months after educational method intervention were analyzed by the SPSS software.

Results: According to the results there is a significant statistical difference between average numbers of models before and after educational intervention ( $\mathrm{p}<0.001)$. Also HbA1c and FBS after educational intervention were lower $(\mathrm{p}<0001)$.

Conclusions: Applying the HBM Model proved is very effective in developing an educational program for diabetics, to control their blood sugar. Besides such programs, follow up education for controlling and monitoring are highly recommended.

Keywords: Health; Health Education; Diabetes; Self Care; Fasting; Hemoglobin A; Glycosylated

\section{Background}

Diabetes mellitus is one of the most common chronic diseases nowadays and is considered a public health problem around the world (1). More than 285 million people in world are diabetic (2) (90\% of them have diabetes type 2 ) which would increase to 439 million people till 2030 (2). The prevalence of diabetes mellitus is increasing in developing countries due to population growth, aging, unhealthy diets, obesity and sedentary lifestyles (3). In developed countries the prevalence of diabetes is reaching $16 \%$ (4). It has been predicted that in year 2025, the number of people with diabetes will be doubled. At this point of those 300 million people with diabetes, $76 \%$ will be living in low income countries (3). World health organization estimated that till 2030 more than 6 million Iranians would be diabetic[5]. Diabetes associated artery disorders cause mortality and morbidity and this disease is one of the most important health problems in the world (5), therefore diabetes control is essential. Control of blood sugar is the basic solution for diabetes control which decreases side effects of the disease (6). International diabetes federation advises the following self-care intervention: 1) proper diet, 2) regular drug consumption, 3) regular exercise and 4) blood sugar monitoring. Benefits of selfcare are increasing life's quality, decreasing expenses and hospital admissions. Follow up decrease chronic and acute disorders or postpone it (7). Studies according to careful models are more effective than common assessments; there are several kinds of theories in health education and one of the models, which is used for diabetic patients self-care is the Health Belief model. This model was introduced by some of psychiatrist in 1950. This theory explains how some people to decrease fear of disease, follow health actions. In this model pure

Implication for health policy/practice/research/medical education:

This paper can contribute to difusion and implementation of health education approach in health planning, health programs and reorienting diabetic centers in Iran.

Copyright (C)2013, Health Promotion Research Center. This is an Open Access article distributed under the terms of the Creative Commons Attribution License(http:/ creativecommons.org/licenses/by/3.0), which permits unrestricted use, distribution, and reproduction in any medium, provided the original work is properly cited. 
benefit should value expenses now days. This model is the most common formal model for health behaviors HBM (8). HBM is explained in four sections including: 1) perceived susceptibility: one's probable morbidity of a disorder or situation, 2) perceived severity: one's belief about a disease, 3 ) perceived benefits: that is the person's understanding about the advantages of doing the preventive behavior in taking certain actions to reduce risk, 4) perceived barriers: each healthy behavior and practice may encounter some barriers and problems (e.g., costs of the advised action). Cues to action (strategies for activating the "readiness" to undertake health actions). Another construction of the health belief model that promotes better coping is self-efficacy. This construction was introduced by Albert Bandera in a social cognitive theory and is simply a person's trust in his ability for successful actions (8). Malanda UL and Daniel MI considered the effect of the health belief model in changing diabetic patients behaviors, which caused a significant change in patients behaviors after educational intervention $(9,10)$. Rubin et al studied the effect of educational program on self-care and metabolic control of 213 patients of diabetic I\&II. After an educational program about self-care (sport, nutrition, blood sugar, monitoring, Insulin level regulation) and metabolic control with glycosylated hemoglobin type A1C (HbA1c) assessment, the results showed that there was a significant difference in self-care behaviors before and six month after education (11). Ahmad khan in a study about self- care and awareness of diabetic patients shows that $56 \%$ of patients have enough awareness about hypoglycemia informally and experimentally, $15 \%$ are aware about chronic disorders, $76 \%$ about self-insulin injection, $10 \%$ about blood sugar levels with glucomoter and $6 \%$ about urine sugar (12). Last port of diabetic treatment is self-treatment thus education about self-care for decrease of disorders seems necessary. Self-care and education is an important method for control of (Fasting Blood Sugar) FBS and HbA1c levels in paients with type 2 diabetes.

\section{Objectives}

The aim of this study was to detect of effect educational program based on health belief model on decreasing blood sugar level of diabetic type 2 female patients of Zahedan city in 2011 - 2012.

\section{Patients and Methods}

The subjects of the study were diabetic type 2 females referred to Hazrat Ali Asghar (A.S) hospital. Number of samples was calculated 69 for each group by using volume of sample formula based on the percent and mean of the variables. Ten percent was increased to this number for probably missing the cases after education. The required sample size needed for this study was computed using the equation:

$$
\mathrm{n}=\frac{\left(\mathrm{Z}_{1-\frac{\alpha}{2}}+\mathrm{Z}_{1-\mathrm{B}}\right)^{2}\left(\mathrm{~S}_{1}^{2}+\mathrm{S}_{2}^{2}\right)}{\mathrm{d}^{2}}
$$

Totally, in the first stage, 138 women took part in two groups case and control (each of group 69 women). The criteria for the study of diabetic type 2 patients, females with an average age of 30 - 60 with at least 1 year history of diabetes, HbA1c more than $7 \%$ during a three months period for hyperglycemia, medical profile at Zahedan Clinic. Without neophyte and other diabetes end organ disorders, the following patients were excluded from the study: pregnant people, type 1 diabetes, diabetic pregnancy, acute visual disorders, and Auto speech disorders.

\subsection{Data Collecting Tool}

Multiparty questionnaire consisted of demographic (8) and awareness (26) questions; 36 questions related to the health belief model construction including, perceived susceptibility ( 6 questions), perceived severity, (5 questions) perceived benefits (6 questions), perceived barriers (5 questions) cue to action (4 questions), self efficacy (10 questions) associated with HbA1c and FBS levels. Record check list was performed for this study and completed during the interview. For the knowledge assessment, 3 optioned questions (yes, no, I don't know) and model construction assessment from like rte sport scale was used. Sensitivity construction numbers, severity and self-efficacy (never, little, middle, strong, very strong) perceived benefits (complete, agreement, complete, disagreement), were scored with the worst being 1 and the best being 5 . For perceived barrier construction (never, little middle, strong, very strong) the reverse (never as 5 and very strong as 1) was considered. For behavior construction rate (zero to 7 times) was questioned for the past week. The content validity of the questionnaire was determined by a panel of reviewers. To determine the internal consistency of the instrument items a Chronbach's Alpha formula was applied to measure the reliability of the questionnaire. The results reveal the reliability rates, which are in an acceptable level (0.76). Before the educational intervention by case control groups, firstly questionnaire and check list were completed and patients were referred to the hospital's lab for HbA1c and FBS detection. After data collection and analysis the educational program based on health belief model was designed. Education intervention for the case group for one month in five educational sections was performed in lectures, playing films, question and answer and diction performed by the education team (researcher, internist, nurse and patient) in the diabetes clinic class. In these sections diabetes disorder, proper diet, walking three times in a 
week for 30 minutes, regular drug intake, blood sugar assessment, diabetic foot care and smoking were assessed. Taught education tools as CD and pamphlets were provided to the patients. The study was conducted after human subject approval was obtained. Participants were assured that their responses would be kept confidential All questionnaire administrators and women were blinded to the conditions of this study. Collected data were analyzed by the SPSS - 15 soft ware. Besides, chi-square test and analytic test, T-test and ANOVA were used for group comparison. The approval of the ethical committee of Tarbiat Modares and Zahedan Medical University was obtained.

\subsection{Findings}

In this experimental study of a female population with type 2 diabetes, attending the hospital diabetes clinic of Hazrat Ali Asghar (AS), confidential sample size of 95\% and at test power of $80 \%$ using the formula for sample size of 100 was calculated for comparison of the two groups. After three months of follow up, forth from the case group and two from the control group were excluded from the study (because of immigration, travel and car accident). The case group had 65 and the control group had 67 individuals. In this study 132 female patients referred to the diabetes clinic of Ali Asghar (A.S) Hospital were studied in a case control manner $(\mathrm{P}>0.5)$. Both groups were the same regarding personal Characteristics, demographic variables such as age, education, marriage, job, type of treatment and segregate smoking. There was no significant difference between the case and control groups $(\mathrm{P}>0.5)$.

Thus, the values were obtained from independent $\mathrm{T}$ tests, chi square and Fisher's exact test, of two groups. From the view point of Waseghi, individuals had no statistically significant differences (Table1).

Table 1. Individual and Test Group Based Information

\begin{tabular}{|c|c|c|c|}
\hline Variable & Test Group, Frequency (\%) & Control Group, Frequency (\%) & Type and Test Result \\
\hline Married status & & & Exact Fisher test, $\mathrm{P}>0.5$ \\
\hline Single & $58(84.1)$ & $59(85.5)$ & \\
\hline married & $11(15.9)$ & $10(14.5)$ & \\
\hline Education level & & & Exact Fisher test, $\mathrm{P}=0.641$ \\
\hline Educated & $46(66.7)$ & $45(66.7)$ & \\
\hline Uneducated & $23(34.8)$ & $24(34.1)$ & \\
\hline Occupational status & & & Exact Fisher test, $\mathrm{P}=0.641$ \\
\hline House holder & $65(94.2)$ & $65(94.2)$ & \\
\hline Employed & $4(5.8)$ & $4(5.8)$ & \\
\hline Type of treatment & & & Pierson, $\mathrm{P}=0.244$ \\
\hline Regime & $6(7.2)$ & $5(7.2)$ & \\
\hline Physical activity & $4(5.8)$ & $4(5.8)$ & \\
\hline Oral drug & $58(84.5)$ & $55(79.7)$ & \\
\hline Insulin & $5(7.8)$ & $5(7.8)$ & \\
\hline Smoking & & & Exact Fisher test, $\mathrm{P}=0.823$ \\
\hline Smoker & $13(18.8)$ & $11(15.9)$ & \\
\hline Non smoker & $56(81.2)$ & $58(84.1)$ & \\
\hline Sources of information & & & Exact Fisher test, $\mathrm{P}>0.5$ \\
\hline Doctors & $60(87)$ & $61(88.4)$ & \\
\hline Health care staff & $9(13)$ & $8(11.6)$ & \\
\hline
\end{tabular}

According to independent T-test, chi-square and Fischer test, there was no significant difference between the case and control groups. According to the ANOVA statical test, there was a significant difference between awareness average and health belief model construction (perceived susceptibility, perceived severity, perceived benefits, perceived barriers and self-efficacy) before and after education intervention in case group (three months and six months). There was a significant difference in independent T-test awareness before intervention between case and control groups $(\mathrm{P}=0.02)$. There was no significant difference in T-test between case and control groups in other constructions $(\mathrm{P}>0.05)$. There was a significant difference $(\mathrm{P}<0.0001)$ according to the ANOVA test between self-care behaviors (diet, physical action, self-monitoring, blood sugar, regular drug in take, diabetic foot care, cigarette smoke) in the control group before and after educational intervention (three months and six months later). However, there was no significant difference $(P>0.05)$ in safe care behavior average. Also in the case group, HbA1c 
average increased to $9.7 \%$ after educational intervention (8.3\% after 3 months and 8.31\% after six months) for which there was a significant difference $(\mathrm{P}<0.0001)$ in the ANOVA test with $95 \%$ assurance. In the case group FBS average increased to 174.82 after educational interventional(134.66 after three months 135.69 after six months) and this was a significant difference $(\mathrm{P}<0.0001)$ in the ANOVA test with $95 \%$ assurance. There was no significant difference $(P>0.5)$ between the case and control group before intervention in both variable (HbA1c and FBS) Table 2.

Table 2. Comparison of Mean and Standard Deviation Scores in the HBM Constructs and the Mean and Standard Deviation of Hemoglobin, Glycogen of Intervention Group and Control Group Before and After Training Invention

\begin{tabular}{|c|c|c|c|c|c|c|}
\hline \multirow{2}{*}{$\begin{array}{l}\text { Study Group Vari- } \\
\text { ables }\end{array}$} & \multirow{2}{*}{$\begin{array}{l}\text { Before Interven- } \\
\text { tion, Mean } \pm \text { SD }\end{array}$} & \multicolumn{2}{|c|}{ Before Intervention, Mean \pm SD } & \multicolumn{2}{|c|}{ After Intervention, Mean \pm SD } & \multirow[t]{2}{*}{ P value } \\
\hline & & 3 Months & 6 Months & 3 Months & 6 Months & \\
\hline \multicolumn{7}{|l|}{ Knowledge } \\
\hline Intervention & $46.46 \pm 5.66$ & $51.76 \pm 2.28$ & $51.78 \pm 2.32$ & $5.3 \pm 3.38$ & $5.32 \pm 3.34$ & $\mathrm{P}<0.001$ \\
\hline Control & $48.59 \pm 4.41$ & $48.59 \pm 4.31$ & $48.69 \pm 4.3$ & $0.1 \pm 0.1$ & $0.1 \pm 0.08$ & $\mathrm{P}=183$ \\
\hline \multicolumn{7}{|l|}{ Susceptibility } \\
\hline Intervention & $16.62 \pm 5.39$ & $21.16 \pm 3.58$ & $21.15 \pm 5.39$ & $4.54 \pm 1.81$ & $4.53 \pm 1.82$ & $\mathrm{P}<0.001$ \\
\hline Control & $17.85 \pm 6.16$ & $17.86 \pm 6.19$ & $17.83 \pm 6.17$ & $0.0 \pm 0.27$ & $0.2 \pm 0.24$ & $\mathrm{P}=485$ \\
\hline \multicolumn{7}{|l|}{ Severity } \\
\hline Intervention & $16.49 \pm 5.08$ & $17.87 \pm 3.39$ & $17.8 \pm 3.38$ & $1.41 \pm 2.89$ & $1.43 \pm 2.89$ & $P<0.001$ \\
\hline Control & $14.83 \pm 4.48$ & $5.41 \pm 14.88$ & $5 \pm 14.86$ & $0.04 \pm 0.36$ & $0.02 \pm 0.38$ & $\mathrm{P}=426$ \\
\hline \multicolumn{7}{|l|}{ Benefits } \\
\hline Intervention & $28.44 \pm 2.57$ & $29.64 \pm 0.99$ & $29.63 \pm 0.99$ & $1.1 \pm 1.74$ & $1.0 .9 \pm 1.75$ & $\mathrm{P}<0.001$ \\
\hline Control & $1.71 \pm 29.22$ & $1.73 \pm 29.17$ & $29.16 \pm 1.72$ & $0.05 \pm 0.36$ & $0.04 \pm 0.38$ & $P=263$ \\
\hline \multicolumn{7}{|l|}{ Barrier } \\
\hline Intervention & $13.94 \pm 3.39$ & $8.96 \pm 2.2$ & $8.95 \pm 2.22$ & $-5.0 \pm 3.31$ & $-5.12 \pm 3.32$ & $\mathrm{P}<0.001$ \\
\hline Control & $12.56 \pm 4.41$ & $4.38 \pm 12.59$ & $12.58 \pm 4.36$ & $0.02 \pm 0.17$ & $0.01 \pm 0.21$ & $\mathrm{P}=351$ \\
\hline \multicolumn{7}{|l|}{ Self-efficacy } \\
\hline Intervention & $29.33 \pm 5.67$ & $42.03 \pm 2.42$ & $41.83 \pm 2.37$ & $12.7 \pm 5.84$ & $12.52 \pm 5.84$ & $\mathrm{P}<0.001$ \\
\hline Control & $30.46 \pm 5.49$ & $30.5 \pm 5.48$ & $30.52 \pm 5.49$ & $0.04 \pm 0.36$ & $0.05 \pm 0.38$ & $\mathrm{P}=373$ \\
\hline \multicolumn{7}{|l|}{ Behavior } \\
\hline Intervention & $29.36 \pm 9.91$ & $39.69 \pm 4.74$ & $39.58 \pm 4369$ & $10.63 \pm 7.69$ & $10.52 \pm 7.78$ & $\mathrm{P}<0.001$ \\
\hline Control & $27.59 \pm 8.95$ & $27.8 \pm 90.9$ & $27.89 \pm 9.09$ & $0.2 \pm 0.89$ & $0.29 \pm 1.07$ & $P=052$ \\
\hline \multicolumn{7}{|l|}{ HbA1c } \\
\hline Intervention & $9.71 \pm 1.81$ & $8.3 \pm 1.17$ & $8.31 \pm 1.17$ & $-1.41 \pm 1.64$ & $-1.14 \pm 1.64$ & $\mathrm{P}<0.001$ \\
\hline Control & $9.04 \pm 1.54$ & $9.06 \pm 1.52$ & $9.07 \pm 1.51$ & $-0.02 \pm 0.08$ & $0.03 \pm 0.08$ & $\mathrm{P}=570$ \\
\hline \multicolumn{7}{|l|}{ FBS } \\
\hline Intervention & $174.82 \pm 35.62$ & $134.66 \pm 17.85$ & $135.69 \pm 16.43$ & $-37.84 \pm 28.08$ & $-38.87 \pm 29.15$ & $\mathrm{P}<0.001$ \\
\hline Control & $176.73 \pm 54.99$ & $177.17 \pm 54.43$ & $178.25 \pm 54.35$ & $-0.44 \pm 3.66$ & $0.52 \pm 3.7$ & $\mathrm{P}=169$ \\
\hline
\end{tabular}

\section{Results}

Less share of diabetic patients in the treatment process can cause treatment failure, patients share is an important factor in the long term, health belief model is a psychiatric model which explains healthy behaviors based on patients beliefs (13). The ideal hypothesis of this study was that health belief model would increase awareness level and promote self-care behaviors in the case group. One finding of this study was that awareness level of patients knowledge and skills from diabetes treatment is necessary for the beginning of the self-control process (14). In this study awareness rate of the case group significantly increased after three and six months. This incensement is the result of education because patient's feedback was clear in the next secessions $(11,12)$, and (15). Result of this study shows incensement of perceived severity, perceived susceptibility and self-efficacy of the case group after education, which is the same as other studies (16-19). According to the ANOVA test perceived benefit construction average is significantly increased and per- 
ceive barrier construction significantly decreased which is same as other studies $(10,20,21)$. In this study behavior such as physical action, regular and on time intake of drugs, blood sugar monitoring, proper diet, and diabetic foot care are considered actions. Before intervention, between case and control groups, there was no significant difference between actions by the ANOVA test, there was a significant difference in the average numbers of self-care behaviors in the case group of educational interventions (3 - 6 months). But in the case group there was no significant increase. Results are coherent with diabetic patient behaviors about on time drug in take $(22,23)$, and proper diet $(24,25)$ also this study is coherent with other research $(26,27)$. The ANOVA test with $95 \%$ assurance showed a significant difference between HbA1c level before and after intervention (3 and 6 months) in the case group. But in the control group, there was no significant difference in HbA1c level before and after intervention, which is the same as previous studies (28-30). There is a significant difference according to the ANOVA test with 95\% assurance between FBS level before and after intervention ( 3 and 6 months) in the case group but not in the FBS levels of the control group before and after intervention. In this study 3 and 6 months after educational intervention, FBS level average in the case group decreased in comparison with the control group, which was due to the educational program and it's efficacy. FBS lever decrease in the case group is the same as other studies $(31,32)$. Limitation of this study was the little cooperation of illiterate patients to take part in the class, in the case group in completing the questionnaires (which was done through the interview of the researcher instead).

\section{Disscusion}

Because education is one of the main principles of health care, in this country designing of educational programs based on models, behavior changing theories of diseases and different aspects of health are more important. Applying the HBM Model proved is very effective in developing an educational program for diabetics, to control their blood sugar. Besides such programs, follow up education for controlling and monitoring are highly recommended.

\section{Acknowledgements}

We acknowledge cooperators of this study. We great appreciate Hazrat Ali Asghar (A.S) and diabetes clinic staff for their faithful cooperation in this research. This research was part of a PhD thesis of Tarbiat Modares University and research in Zahedan University of medical sciences. Research budget was paid by the above centers.

\section{Authors' Contribution}

Iraj Zareban: Designed the reliability assessment of data collection and research writing. shamseddin Niknami, design supervision, reliability and validity assessment and data collection. AliReza Hidarnia, and Fatemeh Rakhshani (advisor) advised about research validity. Mahmood Karimy, helped as a consultant in study design, questionnaires, and revised the final article. Mohsen Shamsi helped as a consultant in study design, questionnaires, and revised the final article.

\section{Financial Disclosure}

There is no financial disclosure.

\section{Funding/Support}

This research was part of a PhD thesis of Tarbiat Modares University and research in Zahedan University of medical sciences. Research budget was paid by the above center.

\section{References}

1. Wild S, Roglic G, Green A, Sicree R, King H. Global prevalence of diabetes: estimates for the year 2000 and projections for 2030. Diabetes Care. 2004;27(5):1047-53.

2. King H, Aubert R, Herman W. Global burden of diabetes, 19952025: prevalence, numerical estimates, and projections. Diabetes Care. 1998;21(9):1414-31.

3. Ketema A, Bisrat T, Lakew A, Tizta T, Eshetu G. Self Care Behavior among Patients with Diabetes in Harari, Eastern Ethiopia: The Health Belief Model Perspective. J SelfCare Behav Patients Diabete. 2012;7(4)

4. Persell SD, Keating NL, Landrum MB, Landon BE, Ayanian JZ, Borbas C, et al. Relationship of diabetes-specific knowledge to selfmanagement activities, ambulatory preventive care, and metabolic outcomes. Prev Med.2004;39(4):746-52

5. Funnell MM, Brown TL, Childs BP, Haas LB, Hosey GM, Jensen B, et al. National Standards for diabetes self-management education. Diabetes Care. 2011;34 Suppl 1:89-96.

6. Mühlhauser I, Müller H. Patientenrelevante Endpunkte und "patien treported outcomes" in klinischer Forschung und medizinischer Praxis. 2009:34-65.

7. Moss SE, Klein R, Klein BE, Meuer SM. The association of glycemia and cause-specific mortality in a diabetic population. Arch Intern Med.1994;154(21):2473-9.

8. Janz NK, Becker MH. The Health Belief Model: a decade later Health Educ Q. 1984;11(1):1-47.

9. Welschen LM, Bloemendal E, Nijpels G, Dekker JM, Heine RJ, Stalman WA. Self-monitoring of blood glucose in patients with type 2 diabetes mellitus who are not using insulin. Cochrane Database Syst Rev. 2005;1(2):CD005060.

10. Daniel M, Messer LC. Perceptions of disease severity and barriers to self-care predict glycemic control in Aboriginal persons with type 2 diabetes mellitus. Chronic Dis Can. 2002;23(4):130-8.

11. Rubin RR, Peyrot M, Saudek CD. Effect of diabetes education on self-care, metabolic control, and emotional well-being. Diabetes Care. 1989;12(10):673-9.

12. Ahmed Khan L, Ahmed Khan S. Level of knowledge and self care in diabetes in a community hospital in najran. Annals of Saudi Medicine. 2000;20(3/4):300-1.

13. Basa RP, Mcleod B. Evaluation of a diabetes specialty center: structure, process and outcome. Patient Educ Couns. 1995;25(1):23-9.

14. Koch J. The role of exercise in the African-American woman with type 2 diabetes mellitus: application of the health belief model.J Am Acad Nurse Pract. 2002;14(3):126-9.

15. Valentine UO, Paul DI, Aihanuwa E. Patients' Knowledge of Diabetes Mellitus in a Nigerian City.J Pharma Res Oct. 2011;10(5):637-42.

16. Davies MJ, Heller S, Skinner TC, Campbell MJ, Carey ME, Cradock 
S. Effectiveness of the diabetes education and self management for ongoing and newly diagnosed (DESMOND) programme for people with newly diagnosed type 2 diabetes: cluster randomised controlled trial. BMJ. 2008;336(7642):491-5.

17. Wabe NT, Angamo MT, Hussein S. Medication adherence in diabetes mellitus and self management practices among type-2 diabetics in Ethiopia. NAm J Med Sci. 2011;3(9):418-23.

18. Assad Zand M, Farsi Z, Najafi Mehri S, Karimi Zarchi A. Research on effect of education in health belief model on health beliefs, awarance and diabetic uptimes behaviors . Iran J Endocrin Metabol. 2006;6(2):169-76.

19. Wofford JL, Smith ED, Miller DP. The multimedia computer for office-based patient education: a systematic review. Patient Educ Couns. 2005;59(2):148-57.

20. Al-Mahroos F, Al-Roomi K, McKeigue PM. Relation of high blood pressure to glucose intolerance, plasma lipids and educational status in an Arabian Gulf population. Int $J$ Epidemiol. 2000;29(1):71-6.

21. Gucciardi E, Demelo M, Lee RN, Grace SL. Assessment of two culturally competent diabetes education methods: individual versus individual plus group education in Canadian Portuguese adults with type 2 diabetes. Ethn Health. 2007;12(2):163-87.

22. Eastman RC, Javitt JC, Herman WH, Dasbach EJ, Copley-Merriman C, Maier W, et al. Model of complications of NIDDM. II. Analysis of the health benefits and cost-effectiveness of treating NIDDM with the goal of normoglycemia. Diabetes Care. 1997;20(5):73544.

23. Tan MY. The relationship of health beliefs and complication prevention behaviors of Chinese individuals with Type 2 Diabetes Mellitus. Diabetes Res Clin Pract. 2004;66(1):71-7.
24. Fortenberry KT, Butler JM, Butner J, Berg CA, Upchurch R, Wiebe DJ. Perceived diabetes task competence mediates the relationship of both negative and positive affect with blood glucose in adolescents with type 1 diabetes. Ann Behav Med. 2009;37(1):1-9.

25. Freedman RR. Chronic insomniacs: replication of Monroe's findings. Psychophysiology. 1987;24(6):721-2.

26. Kochhar A, Nagi M. Effect of supplementation of traditional medicinal plants on blood glucose in non-insulin-dependent diabetics: a pilot study. J Med Food. 2005;8(4):545-9.

27. Tankova T, Dakovska G, Koev D. Education of diabetic patients--a one year experience. Patient Educ Couns. 2001;43(2):139-45.

28. Sarkadi A, Rosenqvist U. Field test of a group education program for type 2 diabetes: measures and predictors of success on individual and group levels. Patient Educ Couns. 2001;44(2):129-39.

29. Vijan S, Hofer TP, Hayward RA. Estimated benefits of glycemic control in microvascular complications in type 2 diabetes. Ann Intern Med.1997;127(9):788-95.

30. Tuomilehto J, Lindstrom J, Eriksson JG, Valle TT, Hamalainen H, Ilanne-Parikka P, et al. Prevention of type 2 diabetes mellitus by changes in lifestyle among subjects with impaired glucose tolerance. N Engl J Med. 2001;344(18):1343-50.

31. Genz J, Haastert B, Meyer G, Steckelberg A, Muller H, Verheyen F, et al. Blood glucose testing and primary prevention of diabetes mellitus type 2--evaluation of the effect of evidence based patient information. BMC Public Health. 2010;10:15.

32. Turner RC, Holman RR, Stratton IM, Cull C A, Matthews DR, Manley SE, et al. Effect of intensive blood-glucose control with metformin on complications in overweight patients with type 2 diabetes (UKPDS 34). UK Prospective Diabetes Study (UKPDS) Group. Lancet. 1998;352(9131):854-65. 